\title{
Effect of exopolysaccharides produced by dairy starter cultures on biofilms formed on reverse osmosis membranes
}

\author{
Nuria Garcia-Fernandez, Ashraf Hassan,* and Sanjeev Anand† $\odot$
}

\section{Graphical Abstract}

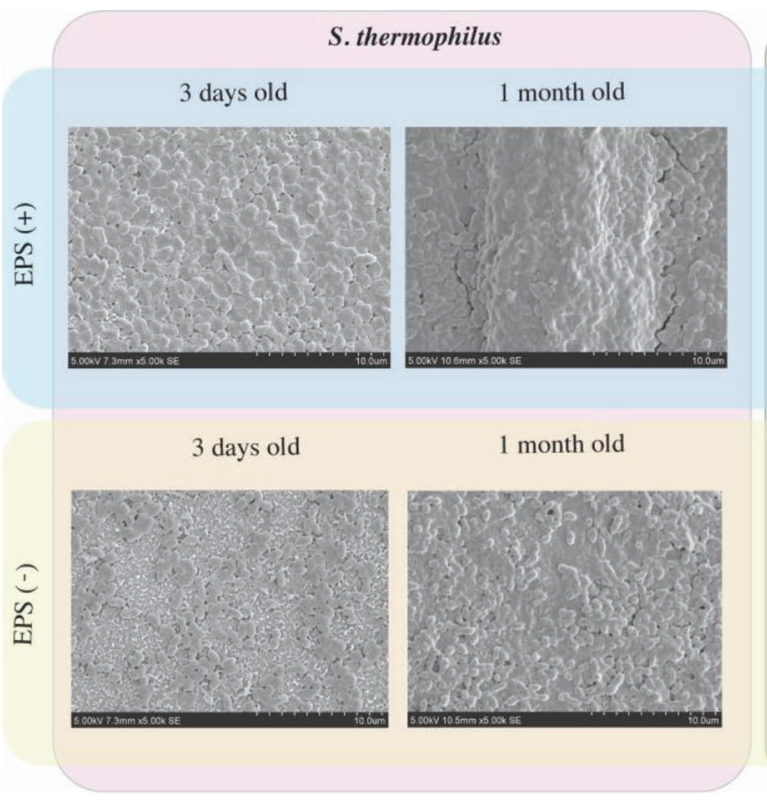

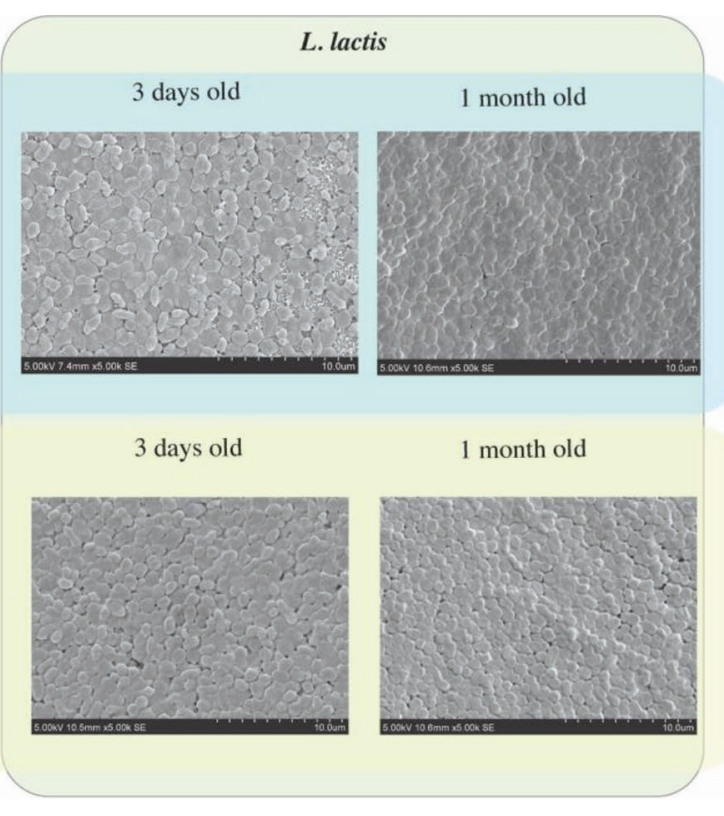

\section{Summary}

The influence of exopolysaccharide (EPS) produced by cheese starter cultures on biofilm formation on reverse osmosis (RO) membranes was assessed using two genera of $\mathrm{EPS}^{+}$cultures and their respective isogenic EPS ${ }^{-}$ mutants by comparing the data between isogenic isolates of the same species only. The study revealed opposite adhesive behavior between both species. High cell surface hydrophobicity showed a greater association with biofilm formation on RO membranes than did surface charge or EPS production.

\section{Highlights}

- Not all EPS-producing starter cultures have an advantage in regard to their ability to form biofilm on membrane separation surfaces.

- Variations between different EPS modify adhesive behavior to reverse osmosis membranes.

- Cell hydrophobicity is critical for initial adhesion to RO membrane separation surface and thus biofilm formation.

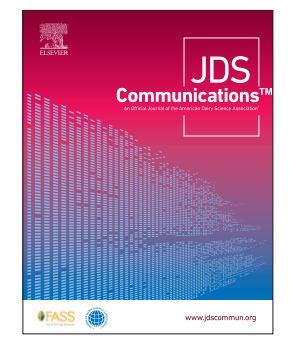




\title{
Effect of exopolysaccharides produced by dairy starter cultures on biofilms formed on reverse osmosis membranes
}

\author{
Nuria Garcia-Fernandez, Ashraf Hassan, ${ }^{*}$ and Sanjeev Anand $+\odot$
}

\begin{abstract}
Two different cheese starter cultures producing exopolysaccharides (EPS ${ }^{+}$: Streptococcus thermophilus strain ST3534 and Lactococcus lactis ssp. cremoris strain JFR+) and their isogenic EPS-negative (EPS ${ }^{-}$: S. thermophilus strain ST5842 and L. lactis ssp. cremoris strain JFR-) variants were used to study the attachment of bacterial cells in the absence of growth (at $4^{\circ} \mathrm{C}$ ) and the resultant biofilm formation on reverse osmosis membranes (at 30 or $35^{\circ} \mathrm{C}$ ). We used M17 broth and a $10 \%$ solution of whey protein concentrate (with 35\% protein) as growth media for biofilm development under static conditions. As expected, ST3534 (EPS ${ }^{+}$) showed significantly greater cell counts within biofilms than ST5842 (EPS ${ }^{-}$). In the absence of growth, however, cells of these 2 isogenic Streptococcus strains attached to the membrane in similar numbers. In contrast, JFR+ counts were significantly lower than those of JFR-under all conditions. These findings indicate that the EPS produced by $S$. thermophilus may play a greater role in building up the 3-dimensional structure of the biofilm, rather than only assisting during initial attachment of the cells to the membrane, whereas the EPS produced by L. lactis ssp. cremoris hampered both initial attachment to the membrane and biofilm formation. Although no differences were observed in the surface charge of the cells between the 2 EPS-producing cultures, surface hydrophobicity was associated with the different adhesive properties of these microorganisms. In conclusion, our results exclude the hypothesis that all EPS-producing starter cultures have an advantage in regard to their ability to form biofilm on membrane separation surfaces. In contrast, variations between different EPS, with hydrophobicity being an important influencing feature, modify adhesive behavior to reverse osmosis membranes.
\end{abstract}

$E^{x}$ opolysaccharide (EPS)-producing lactic acid bacteria (LAB) are relevant to the dairy industry and, with the increased demand for healthier and fat-reduced food products, they have been used as starters to manufacture low-fat products. Exopolysaccharides modify the physical properties of fermented milk by increasing viscosity and water-holding capacity, reducing syneresis, and interfering with protein-protein interactions. These properties together improve smoothness and mouthfeel (Hassan, 2008). Over the last few years, significant work has been done to relate the production of exopolymeric substances by bacteria to biofilm formation. However, the participation of EPS produced by LAB used as dairy starters on biofilm formation remains unexplored. Whey, the liquid byproduct of cheesemaking and casein manufacturing processes and comprising water (93\%), lactose, and whey proteins, is frequently concentrated by reverse osmosis (RO) to reduce the volume and increase the solids content before transportation or further processing. Biofouling, or the buildup of suspended particles, is one of the critical issues in membrane filtration technology (Field, 2010). It has a significantly detrimental effect on the efficiency of the separation processes, causing flux decline, pressure drop, reduced membrane lifetime, and inconsistent product composition and quality. Biofilms play a major role in biofouling and may contribute to product contamination, potentially with harmful bacteria.

Biofilms are initiated when bacterial cells attach to a surface and they develop into different stages of maturation as bacteria grow (Ridgway et al., 1999). The first phase of bacterial adhesion involves physicochemical interactions, after which molecular and cellular interactions take place (Vadillo-Rodriguez et al., 2005). Multiple factors influence the adhesion of bacterial cells, including environmental factors and surface characteristics of the microorganisms and substratum (De Weger et al., 1987; An and Friedman, 1997; Palmer et al., 2007; Kline et al., 2009). Evidence shows that microbial adhesion strongly depends on the hydrophobic-hydrophilic properties of the interacting surfaces (Liu et al., 2004). After the first attachment, strengthening of the bonds occurs, often involving the formation of polymer bridges between the organism and the surface. These sticky polymers form the matrix network, providing mechanical stability to the biofilm (Garrett et al., 2008). The extracellular polymeric substances in biofilms are composed of EPS, glycoproteins, glycolipids, and environmental (e)-DNA (Flemming et al., 2007). Exopolysaccharides produced by microorganisms are typically the most abundant component of the exopolymeric matrix and are believed to have an important role in the structure and stability of biofilms. Bacterial strains that produce EPS are widely used in the dairy manufacturing industry for their added yield and sensory properties. Therefore, it is anticipated that the use of EPS-producing starters in cheese production will yield EPS-containing whey that will deposit on the RO membranes used for whey concentration. The objective of this research was to study the role played by bacterial EPS produced by LAB on cell adhesion and biofilm formation on RO membranes. Our hypothesis was that EPS-producing LAB commonly used for cheese manufacture would form better biofilms than their non-EPS-producing mutants

Department of Dairy and Food Science, Midwest Dairy and Food Research Center, South Dakota State University, Brookings 57007. ${ }^{*}$ Current affiliation: Daisy Brand, Garland, TX 75041. TCorresponding author: sanjeev.anand@sdstate.edu. @ 2021, The Authors. Published by Elsevier Inc. and Fass Inc. on behalf of the American Dairy Science Association ${ }^{\oplus}$. This is an open access article under the CC BY license (http://creativecommons.org/licenses/by/4.0/). Received October 20, 2020. Accepted January 19, 2021. 
because the EPS would support attachment and biofilm formation on the separation membranes used for processing cheese whey.

Two cheese starter cultures (of different genera) producing EPS were compared, respectively, with their isogenic EPS-negative mutants to evaluate the role that EPS production (exclusively) has on their ability to attach and form biofilms on dairy separation membranes. To achieve this goal, we compared the number of cells attached to RO membranes under static conditions when we changed the medium and incubation temperature. Our study avoids the many interacting factors of dynamic settings, and our results will help the dairy industry understand key factors contributing to the initial stage in biofilm formation. In addition, we measured physicochemical characteristics of the $2 \mathrm{EPS}^{+}\lceil$bacterial pairs that affect adhesion to a particular surface, such as surface charge and hydrophobicity. Finally, we observed the biofilm structures under the microscope. The influence of EPS on biofilm formation was compared between isogenic isolates of the same species only.

Streptococcus thermophilus strain ST3534 (EPS ${ }^{+}$) and a mutant S. thermophilus strain ST5842 (EPS $)$ were provided by Chr. Hansen Inc. Lactococcus lactis ssp. cremoris strain JFR+ $\left(\mathrm{EPS}^{+}\right)$was isolated from commercial buttermilk, and we isolated a spontaneous mutant L. lactis ssp. cremoris strain JFR- (EPS ${ }^{-}$) in our laboratory. For selection of the JFR EPS ${ }^{-}$mutants, 3 replicate clones of strain JFR+ were inoculated into tubes with $10 \mathrm{~mL}$ of M17 broth (Oxoid) and incubated to stationary phase at $30^{\circ} \mathrm{C}$ under static conditions. One loopful of the top layer of the liquid culture was collected and aseptically transferred to another tube with $10 \mathrm{~mL}$ of fresh medium, which was incubated under the same conditions. This was repeated over a period of $10 \mathrm{~d}$, and the cultures were checked for colony morphology daily. Eventually, we observed colonies of the same morphology, but lacking ropiness, and we isolated one such colony. This mutant lost the ability to ferment lactose ( $\left.\mathrm{Lac}^{-}\right)$along with the EPS operon. The identity of this $\mathrm{Lac}^{-}$strain as L. lactis ssp. cremoris, was confirmed by plasmid profile comparison and MALDI-TOF analysis at the Animal Disease Diagnostic and Research Laboratory of South Dakota State University (Brookings). In all experiments conducted with the $\mathrm{EPS}^{-} \mathrm{Lac}^{-}$strain, glucose was added to the growth medium, as described below.

The RO membrane used in this study was obtained from Toray Membrane USA Inc. This membrane was made of cross-linked aromatic polyamide with a negative net charge and was hydrophilic. Each of the 5 pieces used to develop biofilms in a typical experiment consisted of 2 membrane squares $\left(2 \times 2 \mathrm{~cm}^{2}\right)$ that were glued together to expose the retentate sides. These were pretreated by soaking in sterile distilled water for $5 \mathrm{~d}$ with daily water changes and sanitizing with hydrogen peroxide $(0.5 \%$ solution) followed by rinsing with sterile distilled water 3 times and placing in a sterile Petri dish for further use.

To study biofilm formation, standard static assays were conducted in Petri dishes using 2 different growth media. Fifty milliliters of M17 broth with $5 \%$ lactose or a $10 \%$ solution of whey protein concentrate (WPC) with 35\% protein (WPC35) was inoculated with $1 \mathrm{~mL}$ of culture in late-exponential phase, containing $10^{8} \mathrm{cfu} /$ $\mathrm{mL}$ of the test strain, and was added to the Petri dish containing the membrane pieces as described above. The incubation was carried out for $24 \mathrm{~h}$ under static conditions at $30^{\circ} \mathrm{C}$ (for $\mathrm{JFR}+/ \mathrm{JFR}-$ ) or $35^{\circ} \mathrm{C}$ (for ST3534/ST5842) to develop biofilms. To study at- tachment in the absence of growth, $50 \mathrm{~mL}$ of M17 broth with 5\% lactose containing $10^{8} \mathrm{cfu} / \mathrm{mL}$ of the test strain was incubated for $24 \mathrm{~h}$ under static conditions at $4^{\circ} \mathrm{C}$. The broth or whey medium was supplemented with $2.5 \%$ glucose only for JFR- (EPS ${ }^{-} \mathrm{Lac}^{-}$), to achieve the same sugar molality that was in the $5 \%$ lactose medium for JFR+. No significant differences were found in the growth rate between JFR+ and its genetic variant in all media used under these conditions (data not shown).

The ability of each strain to attach in absence of growth (at $4^{\circ} \mathrm{C}$ ) or form biofilm was evaluated by estimating the number of viable cells embedded in the membranes after mechanically detaching cells. The membrane pieces were rinsed 3 times in distilled water to remove loosely attached cells (Hinsa-Leasure et al., 2013), and cells were detached from membranes by mixing in a stomacher at $230 \mathrm{rpm}$ for $2 \mathrm{~min}$. Counts of viable cells were determined by enumeration of colony-forming units on M17 agar after incubation for $24 \mathrm{~h}$ at the respective growth temperatures.

For the $\mathrm{EPS}^{+} / \mathrm{EPS}^{-}$cultures, surface structures associated with attachment (pili, fimbriae, flagella, and capsule) were examined microscopically. Furthermore, the biofilm structure of 3-d-old and 1-mo-old membranes was observed using scanning electron microscopy.

For the observations of surface structures by transmission electron microscopy, bacterial cells were placed on formvar carboncoated 100-mesh copper grids (Electron Microscopy Sciences) and left to settle for $5 \mathrm{~min}$. The excess liquid and any unbound cells were wicked off with a No. 1 Whatman filter wedge. A drop of $1 \%$ aqueous uranyl acetate was placed on each grid, grids were air-dried before imaging on a FEI Tecnai2 0 transmission electron microscope (FEI Inc.) operating at $200 \mathrm{keV}$, and images were taken digitally with an AMT camera (AMT Imaging).

For the observations of bacterial capsules, confocal scanning laser microscopy was used. Overnight cultures of the $\mathrm{EPS}^{+}$and EPS $^{-}$strains separately grown in M17 broth were suspended at $10 \%(\mathrm{vol} / \mathrm{vol})$ in reconstituted skim milk that was heat-treated at $95^{\circ} \mathrm{C}$ for $15 \mathrm{~min}$, and 1 drop of each milk suspension was deposited on a glass slide and observed with an Olympus Fluoview FV300 CSLM (Olympus America) in reflectance mode as previously described (Hassan et al., 1995).

The structure of biofilms on RO membranes was observed by scanning electron microscopy. We developed 3-d-old and 1-moold biofilms on RO membrane pieces as described above by inoculating individual cultures of ST3534, ST5842, JFR+, and JFR - strains in M17 broth with 5\% lactose as the growth medium. In the case of the JFR EPS ${ }^{-} \mathrm{Lac}^{-}$mutant, lactose was substituted by $2.5 \%$ glucose. Membrane pieces were incubated under aerobic static conditions at $36^{\circ} \mathrm{C}$ (ST cultures) or $30^{\circ} \mathrm{C}$ (JFR cultures). Membrane biofilms at $3 \mathrm{~d}$ or 1 mo of age were observed, as described by Hassan et al. (2010), using a Hitachi scanning electron microscope (model S-3400N, Hitachi Systems Ltd.).

Microbial adhesion to hydrocarbon (MATH) was performed to determine cell surface hydrophobicity (Rosenberg, 1984). One milliliter of xylene was added to $4 \mathrm{~mL}$ of cells of overnight cultures suspended in PBS, vortexed for $2 \mathrm{~min}$, and equilibrated at $37^{\circ} \mathrm{C}$ for $30 \mathrm{~min}$. The optical density at $600 \mathrm{~nm}\left(\mathrm{OD}_{600 \mathrm{~mm}}\right)$ of a portion of the aqueous lower layer before and after treatment with xylene was determined using a Cary 50 Bio spectrophotometer (Varian). 
Table 1. Counts of exopolysaccharide-producing $\left(\mathrm{EPS}^{+}\right)$and nonproducing $\left(\mathrm{EPS}^{-}\right)$cultures in biofilms formed on reverse osmosis membranes under static conditions using different feed substrates and counts of cells attached in the absence of growth ${ }^{1}$

\begin{tabular}{|c|c|c|c|c|c|}
\hline \multirow[b]{2}{*}{ Substrate and incubation condition } & \multirow[b]{2}{*}{ Culture } & \multicolumn{2}{|c|}{$\begin{array}{l}\text { Streptococcus } \\
\text { thermophilus }\end{array}$} & \multicolumn{2}{|c|}{$\begin{array}{l}\text { Lactococcus lactis ssp } \\
\text { cremoris }\end{array}$} \\
\hline & & Count & SD & Count & SD \\
\hline \multirow{2}{*}{$\begin{array}{l}\text { Biofilm formation using M17 as growth } \\
\text { medium }\end{array}$} & $\mathrm{EPS}^{+}$ & $6.46^{\mathrm{a}}$ & 0.13 & $4.55^{\mathrm{b}}$ & 0.29 \\
\hline & $\mathrm{EPS}^{-}$ & $5.50^{\mathrm{b}}$ & 0.33 & $6.02^{\mathrm{a}}$ & 0.44 \\
\hline \multirow{2}{*}{$\begin{array}{l}\text { Biofilm formation using whey protein } \\
\text { concentration as growth medium }\end{array}$} & $\mathrm{EPS}^{+}$ & $5.96^{\mathrm{a}}$ & 0.25 & $4.33^{\mathrm{a}}$ & 0.32 \\
\hline & $\mathrm{EPS}^{-}$ & $5.22^{\mathrm{b}}$ & 0.3 & $5.67^{\mathrm{b}}$ & 0.6 \\
\hline \multirow{2}{*}{$\begin{array}{l}\text { Attachment with } \mathrm{M} 17 \text { in absence of growth } \\
\text { at } 4^{\circ} \mathrm{C}\end{array}$} & $\mathrm{EPS}^{+}$ & $5.92^{\mathrm{a}}$ & 0.6 & $4.78^{b}$ & 0.21 \\
\hline & $\mathrm{EPS}^{-}$ & $6.12^{\mathrm{a}}$ & 0.5 & $6.16^{\mathrm{a}}$ & 0.22 \\
\hline
\end{tabular}

${ }^{a, b}$ Means in the same column without common superscripts are significantly different $(P \leq 0.05)$.

${ }^{1}$ Counts $\left(\log _{10} \mathrm{cfu} / \mathrm{cm}^{2}\right)$ are means of 3 replicates.

Hydrophobicity was calculated as follows: MATH value $(\%)=$ $\left(\mathrm{OD}_{600}\right.$ before treatment $-\mathrm{OD}_{600}$ after treatment $) \times 100 / \mathrm{OD}_{600}$ before treatment.

Absolute cell surface hydrophobicity was determined by measuring contact angle on intact colonies grown on M17 agar plates by the sessile drop technique (Woodward, 1999). A lawn of cells was created by plating $1 \mathrm{~mL}$ of an overnight culture and incubating the plate for $12 \mathrm{~h}$ at the appropriate growth temperature. A crosssection of 75 by $25 \mathrm{~mm}$ of the agar was then cut with a scalpel and placed on a glass slide. A drop of $10 \mu \mathrm{L}$ of sterile distilled water was placed on the surface of the agar plate, and an image was taken at an angle of $0^{\circ}$ so that it looked exactly horizontally at the drop using a Canon EOS Rebel T1i camera with an EF-S 18-200mm f/3.5-5.6 IS standard zoom lens. The static contact angle was measured using ImageJ software (National Institutes of Health) by manual point selection. If the contact angle was $<90^{\circ}$, the cell surface was considered hydrophilic; if the contact angle was $>90^{\circ}$, the cell surface was considered hydrophobic. Reported values are the averages of triplicate contact angle measurements.

The zeta potential of bacterial cells was also measured. The 4 cultures were grown on M17 incubated at $35^{\circ} \mathrm{C}$ (ST cultures) or $30^{\circ} \mathrm{C}$ (JFR cultures). Medium contained $0.5 \%$ lactose for ST3534 and ST5842, 5\% lactose for JFR+, and 2.5\% glucose for JFR-. Cells were washed twice in PBS, and the last suspension was prepared immediately before measurement. Surface charges at different ionic strengths were measured for cells obtained from overnight cultures in M17 $\left(10^{7} \mathrm{cfu} / \mathrm{mL}\right)$ suspended in 1,5 , or 10 $\mathrm{m} M$ solutions of PBS at pH 7.4 (Hassan and Frank, 2004). Eight hundred microliters of the cell suspension freshly prepared was pipetted into a disposable capillary cell. Zeta potentials were measured at $25^{\circ} \mathrm{C}$ using the Zetasizer Nano series instrument (Malvern Instruments Ltd.).

All experiments were repeated in 3 separate experiments. Statistical analysis was completed using the SAS 9.3 (TS LEVEL 1M0 W32_7PRO platform; SAS Institute Inc.). The pairwise comparisons between treatments were performed using a Student's $t$-test to examine whether biofilm formation differed significantly among EPS-producing and non-EPS-producing groups. The ANOVA test was performed to determine significant differences between more than 2 groups. Means were considered statistically significant at $P<0.05$
The EPS-producing strain of S. thermophilus (ST3534) formed more biofilm than its EPS ${ }^{-}$mutant. In contrast, L. lactis ssp. cremoris strain JFR+ formed less biofilm than its EPS ${ }^{-}$mutant (Table 1). Growth medium (M17 or WPC) did not affect the attachment of the 2 isogenic pairs, although the differences between the EPS and EPS $^{-}$strains were less dramatic in WPC than in M17 broth. When only the attachment of bacterial cells to RO membranes was studied in absence of growth $\left(\right.$ at $\left.4^{\circ} \mathrm{C}\right)$, no significant difference $(P$ $<0.05)$ was observed between the EPS ${ }^{+}$and EPS ${ }^{-} S$. thermophilus (Table 1), indicating that the EPS produced by this strain influenced cell-cell cohesion, rather than cell-membrane adhesion. Interestingly, EPS produced by strain JFR + seemed to interfere with attachment, as we observed a significantly greater number of cells of JFR - attached to the RO membrane (Table 1), suggesting that the EPS produced by this strain interferes with both cell surface adhesion and cell-cell cohesion. Although, to our knowledge, the role of EPS produced by LAB in biofilms formation on dairy membranes has not been studied, EPS has long been associated with strong adhesion and biofilms formed by diverse bacteria on various surfaces (Quintero and Weiner, 1995; Langille et al., 2000; Michel et al., 2011).

All 4 strains were negatively charged, and both $\mathrm{EPS}^{+}$cultures had a greater negative charge than their respective EPS ${ }^{-}$genetic variants (Table 2). Hence, cell charge alone did not appear to play a major role in attachment to the RO membrane. Contact angle revealed the hydrophilic character of all cell surfaces. However, different degrees of water affinity were observed between the genetic pairs (Table 2). The JFR+ strain was more hydrophilic (low adhesion to xylene) than its genetic variant, whereas ST3534 was significantly less hydrophilic than its $\mathrm{EPS}^{-}$mutant $(P<0.05)$. The MATH results agreed with the contact angle results, with ST3534 and JFR - showing greater adhesion to xylene than their respective variant strains. Cell hydrophobicity and biofilm development were positively correlated, which could explain the difference between the 2 EPS $^{+}$cultures (Tables 1 and 2). The higher hydrophilicity of the JFR+ culture than its EPS ${ }^{-}$mutant was associated with EPS production, which seemed to interfere with attachment of bacterial cells to the membrane. This strain exhibited stronger affinity for the liquid medium than for the membranes. Carbohydrates are viewed as entirely polar molecules; however, it has been demonstrated that hydrophobic and van der Waals interactions are involved in interac- 
Table 2. Hydrophobicity as determined by microbial adhesion to hydrocarbon (MATH; xylene) and zeta potential (mV) under different ionic strengths of cell surface of exopolysaccharide-producing $\left(\right.$ EPS $\left.^{+}\right)$and nonproducing (EPS ${ }^{-}$) cultures ${ }^{1}$

\begin{tabular}{|c|c|c|c|c|c|c|}
\hline \multirow[b]{2}{*}{ Strain $^{2}$} & \multirow[b]{2}{*}{ Contact angle } & \multicolumn{2}{|c|}{ Cells bound to xylene ${ }^{3}(\%)$} & \multicolumn{3}{|c|}{ Zeta potential at different PBS concentration } \\
\hline & & Biofilm & Attachment & $1 \mathrm{mM}$ & $5 \mathrm{mM}$ & $10 \mathrm{mM}$ \\
\hline ST3534 & $34.59^{\mathrm{a}}$ & $48.61^{\mathrm{a}}$ & $55.89^{\mathrm{a}}$ & $-19.03^{\mathrm{a}}$ & $-11.83^{\mathrm{a}}$ & $-10.57^{\mathrm{a}}$ \\
\hline ST5842 & $14.30^{c}$ & $10.41^{b}$ & $18.98^{b}$ & $-6.52^{c}$ & $-4.83^{c}$ & $-4.05^{\mathrm{c}}$ \\
\hline JFR+ & $12.84^{c}$ & $3.47^{\mathrm{b}}$ & $0^{b}$ & $-18.33^{\mathrm{a}}$ & $-12.6^{\mathrm{a}}$ & $-9.74^{\mathrm{a}}$ \\
\hline JFR- & $24.12^{b}$ & $76.55^{\mathrm{a}}$ & $84.63^{a}$ & $-10.31^{b}$ & $-7.96^{\mathrm{b}}$ & $-5.72^{b}$ \\
\hline
\end{tabular}

${ }^{a-c}$ Means in the same column without common superscripts are significantly different $(P \leq 0.05)$.

${ }^{1}$ Data are means of 3 replicates.

${ }^{2}$ EPS-producing strains Streptococcus thermophilus ST3534 and Lactococcus lactis ssp. cremoris strain JFR+ and their isogenic non-EPS-producing variants S. thermophilus ST5842 and L. lactis ssp. cremoris JFR-.

${ }^{3} \mathrm{MATH}$ was measured under same conditions used in biofilm formation and attachment experiments.

tions between carbohydrates and proteins (Quiocho, 1988). Generally, the increase in cell surface hydrophobicity of EPS-producing starters resulted in more intense biofilm formation, suggesting that hydrophobicity of EPS plays a major role in biofilm formation on $\mathrm{RO}$ membranes. This observation is consistent with the description of super-sticky yeast strains having high contact angle and surface tension (Nguyen et al., 2004).

To confirm that the differences in attachment and biofilm formation between the EPS ${ }^{+}$strains and their $\mathrm{EPS}^{-}$mutants could be attributed only to EPS production, we conducted additional phenotypic studies. The studies showed that no attachment structures were found on the cell wall of any of the 4 strains, as observed by transmission electron microscopy (data not shown). Capsules (depicting cell-associated EPS) were observed in the $2 \mathrm{EPS}^{+}$cultures but not in their respective mutants. In addition, no growth rate differences were found between the genetic pairs (data not shown).

Microscopic observations provided confirmation of the enumeration data. Scanning electron micrographs of 3-d-old and 1-mo-old biofilms are shown in Figure 1. The 3-d-old biofilm formed by all strains consisted of a monolayer of cocci. Images showed larger areas covered by cells of ST3534 than by ST5842. In contrast, larger areas covered by cells were observed in biofilms formed by JFR - than by JFR+. The greater biofilm formed by ST3534 and JFR - than their respective paired strains, as observed by microscopy, agreed with the enumeration data (Table 1). Whereas individual spherical cells of EPS ${ }^{-}$strains were observed, cells of the EPS strains were embedded in a matrix of EPS (Figure 1).

In the 1-mo-old biofilm, only ST3534 seemed to form a 3-dimensional structure consisting of hills and valleys similar to those observed by Hassan et al. (2010) on used industrial membranes. Significantly fewer cells of ST5842 than ST3534 were observed on the surface of the membrane. Images also show that the presence of EPS produced by ST3534 resulted not only in a more extensive biofilm but also in different structures from those produced by other cultures. Finally, the JFR- culture formed biofilm consisting of flat multilayer cells, whereas fewer cells of JFR+ were glued by EPS that appeared to be a single-layer biofilm.

The differences in adhesive behavior between the 2 EPS-producing cultures were likely due to variations in the molecular characteristics of the respective EPS, such as composition, molecular weight, charge, and branching. The JFR+ strain produces EPS that is highly hydrophilic and has high water-binding capacity, which are desirable characteristics in yogurt, but slimy EPS can cause an adverse slippery mouthfeel in some fermented milks (Hassan, 2008). Beta-linkages have been associated with stiff chains and hence high consistency of EPS solutions (Laws and Marshall, 2001). Also, acidic groups on the EPS provide the ability to interact electrostatically with cations and to enter into hydrophobic interactions (Marshall et al., 1989).

The production of EPS has been shown to be crucial for the architecture of some biofilms (Danese et al., 2000). Bacteria producing hydrophobic EPS could not only form stronger biofilms but also resist antimicrobial agents, as they would exclude these agents that are normally in aqueous solutions. Recently it was suggested that some bacteria produce EPS to stimulate biofilm formation as a survival mechanism (Yu et al., 2016). The suppression of biofilm by disrupting bacterial communication or EPS production are research areas that offer opportunities for future implementation in dairy and nondairy membrane systems (Mansouri et al., 2010). This approach has potential for the dairy industry but needs further investigation. A more readily applicable solution that we are investigating is the application of enzymes that specifically hydrolyze biofilm-supporting EPS to facilitate the removal of foulants by cleaning-in-place systems.

In conclusion, EPS produced by LAB may enhance biofilm or interfere with attachment and biofilm formation, depending on their physicochemical characteristics. Strain ST3534 produced EPS that supported biofilm formation, whereas strain JFR+ produced EPS with lowered attachment ability and biofilm formation. The growth medium did not affect the tendency of the test strains to form a biofilm. The variability in bacterial cell surface charge did not seem to affect attachment or biofilm formation by these organisms on RO membranes. Generally, high cell surface hydrophobicity was associated with greater biofilm formation on RO membranes. This study highlights the importance of bacterial cell-membrane surface hydrophobic-hydrophilic interactions in the initial stages of biofilm formation under static conditions. More research needs to be conducted to determine whether these results can be extrapolated to real membrane filtration processes. Nevertheless, the study provides new insights on potential biofilm formation by starter cultures and suggests possible control of biofouling by manipulating the membrane surface chemistry based on the type of starter culture used. 


\section{3-d-old biofilm}
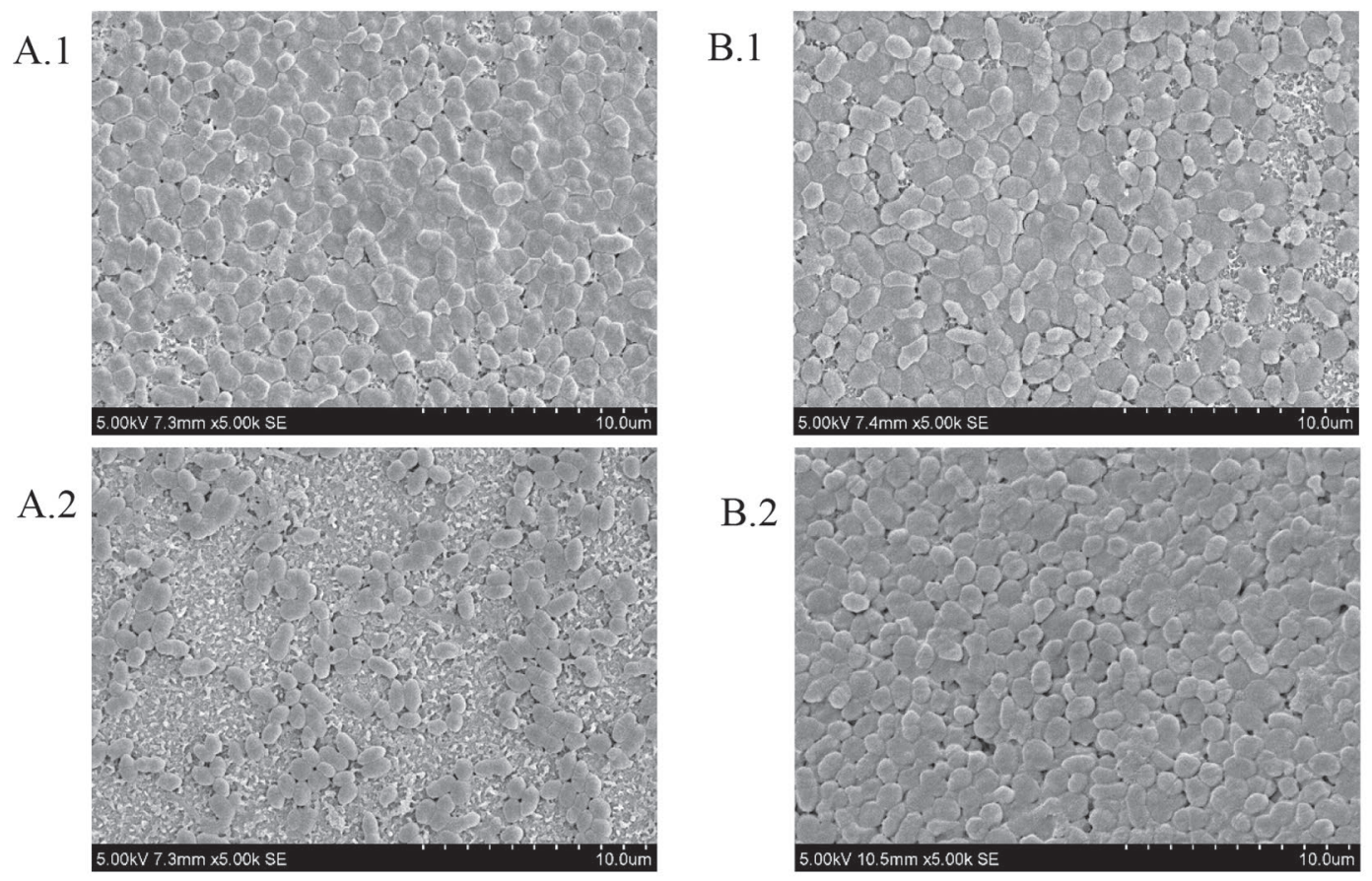

B.2

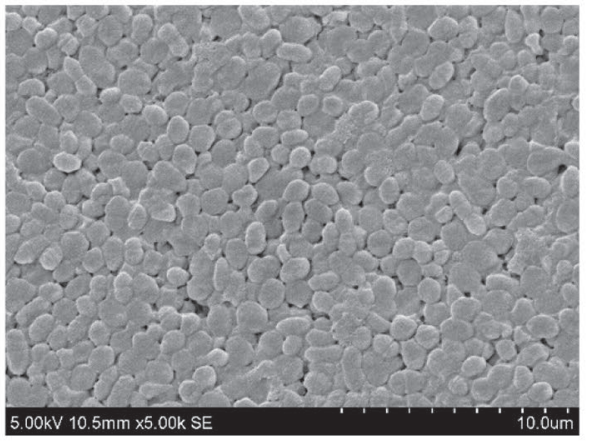

1-mo-old biofilm

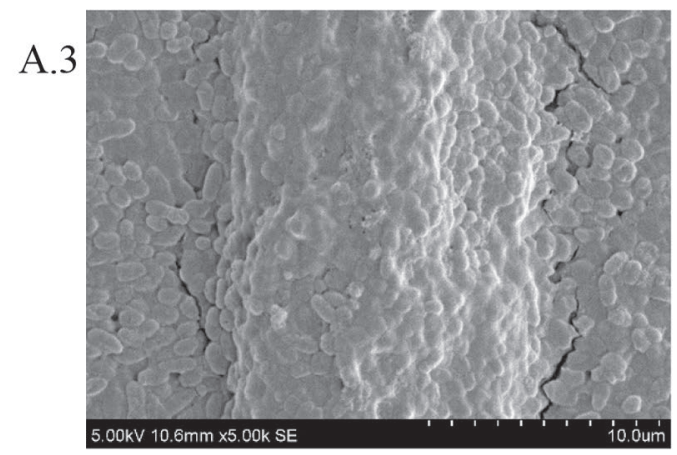

B.3
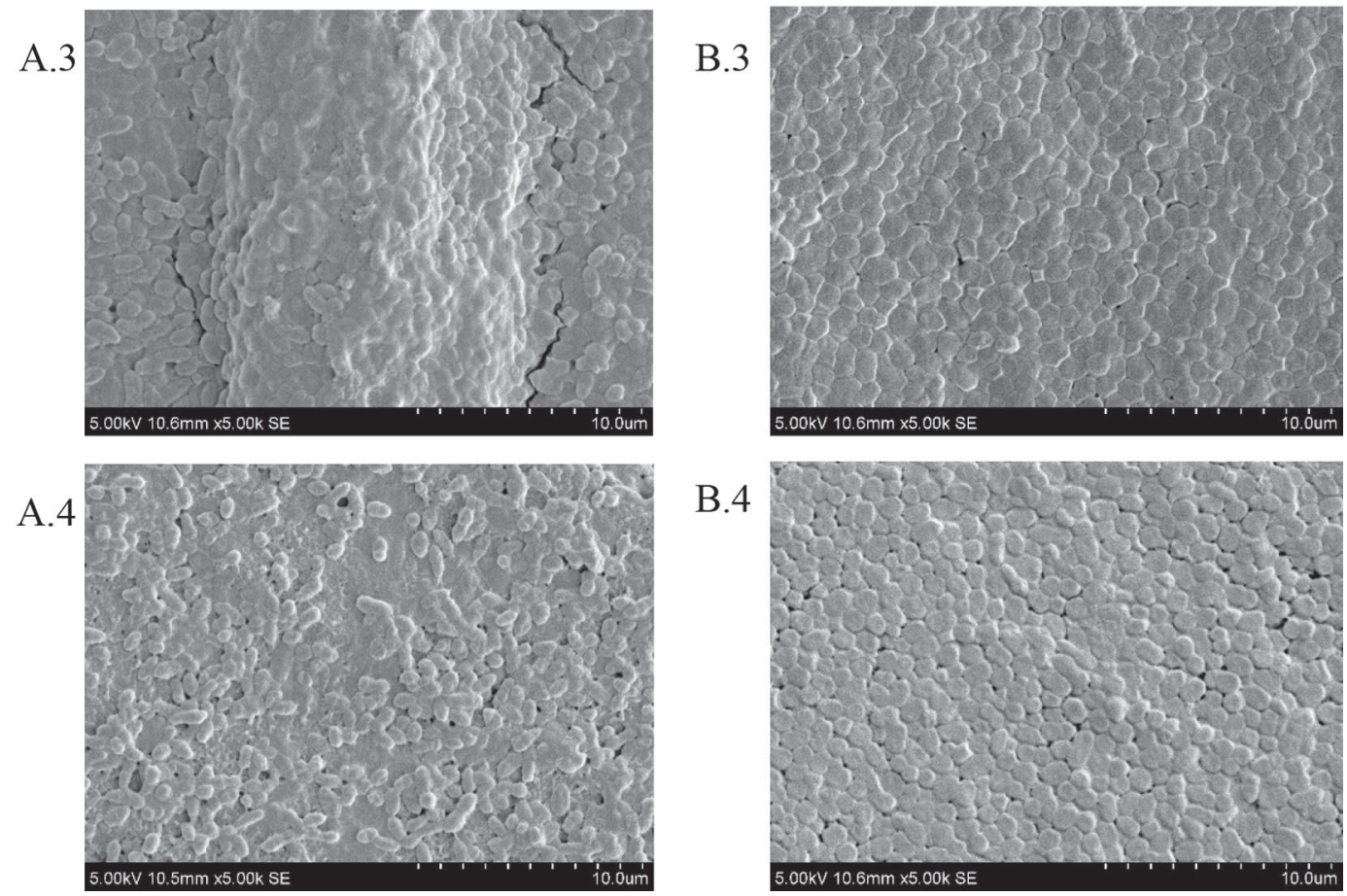

B.4

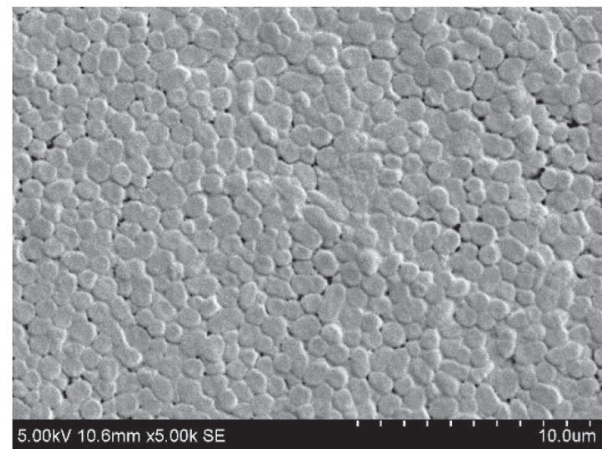

Figure 1. Scanning electron micrographs of 3-d-old and 1-mo-old biofilms of exopolysaccharide (EPS)-producing strains Streptococcus thermophilus ST3534 (A.1, A.3) and Lactococcus lactis ssp. cremoris strain JFR+ (B.1, B.3) and their isogenic EPS ${ }^{-}$variants S. thermophilus ST5842 (A.2, A.4) and L. lactis ssp. cremoris JFR- (B.2, B.4) on reverse osmosis membranes under static conditions. 


\section{References}

An, Y. H., and R. J. Friedman. 1997. Laboratory methods for studies of bacterial adhesion. J. Microbiol. Methods 30:141-152. https://doi.org/10.1016/ S0167-7012(97)00058-4.

Danese, P. N., L. A. Pratt, and R. Kolter. 2000. Exopolysaccharide production is required for development of Escherichia coli $\mathrm{K}-12$ biofilm architecture. J. Bacteriol. 182:3593-3596. https://doi.org/10.1128/JB.182.12.3593-3596 .2000 .

De Weger, L. A., C. I. van der Vlugt, A. H. Wijfjes, P. A. Bakker, B. Schippers, and B. Lugtenberg. 1987. Flagella of a plant-growth-stimulating Pseudomonas fluorescens strain are required for colonization of potato roots. J. Bacteriol. 169:2769-2773. https://doi.org/10.1128/JB.169.6.2769-2773 .1987.

Field, R. 2010. Fundamentals of fouling. Pages 1-23 in Membranes for Water Treatment. Vol. 4. Wiley-VCH Verlag \& Co. KGaA.

Flemming, H. C., T. R. Neu, and D. J. Wozniak. 2007. The EPS matrix: The "house of biofilm cells". J. Bacteriol. 189:7945-7947. https://doi.org/10 .1128/JB.00858-07.

Garrett, T. R., M. Bhakoo, and Z. B. Zhang. 2008. Bacterial adhesion and biofilms on surfaces. Prog. Nat. Sci. 18:1049-1056. https://doi.org/10.1016/j .pnsc.2008.04.001.

Hassan, A. N. 2008. ADSA Foundation Scholar Award: Possibilities and challenges of exopolysaccharide-producing lactic cultures in dairy foods. J. Dairy Sci. 91:1282-1298. https://doi.org/10.3168/jds.2007-0558.

Hassan, A. N., S. Anand, and M. Avadhanula. 2010. Microscopic observation of multispecies biofilm of various structures on whey concentration membranes. J. Dairy Sci. 93:2321-2329. https://doi.org/10.3168/jds.2009-2800.

Hassan, A. N., and J. F. Frank. 2004. Attachment of Escherichia coli O157:H7 grown in tryptic soy broth and nutrient broth to apple and lettuce surfaces as related to cell hydrophobicity, surface charge, and capsule production. Int. J. Food Microbiol. 96:103-109. https://doi.org/10.1016/S0168 $-1605(03) 00160-0$.

Hassan, A. N., J. F. Frank, M. A. Farmer, K. A. Schmidt, and S. I. Shalabi. 1995. Observation of encapsulated lactic acid bacteria using confocal scanning laser microscopy. J. Dairy Sci. 78:2624-2628. https://doi.org/10.3168/jds .S0022-0302(95)76891-6.

Hinsa-Leasure, S. M., C. Koid, J. M. Tiedje, and J. N. Schultzhaus. 2013. Biofilm formation by Psychrobacter arcticus and the role of a large adhesin in attachment to surfaces. Appl. Environ. Microbiol. 79:3967-3973. https:// doi.org/10.1128/AEM.00867-13.

Kline, K. A., S. Falker, S. Dahlberg, S. Normark, and B. Henriques-Normark. 2009. Bacterial adhesins in host-microbe interactions. Cell Host Microbe 5:580-592. https://doi.org/10.1016/j.chom.2009.05.011.

Langille, S. E., G. G. Geesey, and R. M. Weiner. 2000. Polysaccharide-specific probes inhibit adhesion of Hyphomonas rosenbergii strain VP-6 to hydrophilic surfaces. J. Ind. Microbiol. Biotechnol. 25:81-85. https://doi.org/10 .1038/sj.jim.7000033.

Laws, A. P., and V. M. Marshall. 2001. The relevance of exopolysaccharides to the rheological properties in milk fermented with ropy strains of lactic acid bacteria. Int. Dairy J. 11:709-721. https://doi.org/10.1016/S0958 -6946(01)00115-7.

Liu, Y., S. F. Yang, Y. Li, H. Xu, L. Qin, and J. H. Tay. 2004. The influence of cell and substratum surface hydrophobicities on microbial attachment. J. Biotechnol. 110:251-256. https://doi.org/10.1016/j.jbiotec.2004.02.012.

Mansouri, J., S. Harrisson, and V. Chen. 2010. Strategies for controlling biofouling in membrane filtration systems: challenges and opportunities. J. Mater. Chem. 20:4567-4586. https://doi.org/10.1039/b926440j.
Marshall, P. A., G. I. Loeb, M. M. Cowan, and M. Fletcher. 1989. Response of microbial adhesives and biofilm matrix polymers to chemical treatments as determined by interference reflection microscopy and light section microscopy. Appl. Environ. Microbiol. 55:2827-2831. https://doi.org/10 .1128/AEM.55.11.2827-2831.1989.

Michel, C., F. Garrido, E. Roche, S. Challan Belval, and M. C. Dictor. 2011. Role of exopolymeric substances (EPS) in the stability of the biofilm of Thiomonas arsenivorans grown on a porous mineral support. J. Microbiol. Biotechnol. 21:183-186. https://doi.org/10.4014/jmb.1001.01017.

Nguyen, B., A. Upadhyaya, A. van Oudenaarden, and M. P. Brenner. 2004. Elastic instability in growing yeast colonies. Biophys. J. 86:2740-2747. https://doi.org/10.1016/S0006-3495(04)74327-1.

Palmer, J., S. Flint, and J. Brooks. 2007. Bacterial cell attachment, the beginning of a biofilm. J. Ind. Microbiol. Biotechnol. 34:577-588. https://do .org/10.1007/s10295-007-0234-4.

Quintero, E. J., and R. M. Weiner. 1995. Physical and chemical characterization of the polysaccharide capsule of the marine bacterium, Hyphomonas strain Mhs-3. J. Ind. Microbiol. 15:347-351. https://doi.org/10.1007/ BF01569990

Quiocho, F. A. 1988. Molecular features and basic understanding of proteincarbohydrate interactions: The arabinose-binding protein-sugar complex. Curr. Top. Microbiol. Immunol. 139:135-148. https://doi.org/10.1007/978 $-3-642-46641-05$

Ridgway, H., K. Ishida, G. Rodriguez, J. Safarik, T. Knoell, and R. Bold. 1999. Biofouling of membranes: Membrane preparation, characterization, and analysis of bacterial adhesion. Methods Enzymol. 310:463-494. https://doi .org/10.1016/S0076-6879(99)10036-3.

Rosenberg, M. 1984. Bacterial adherence to hydrocarbons: A useful technique for studying cell surface hydrophobicity. FEMS Microbiol. Lett. 22:289 295. https://doi.org/10.1111/j.1574-6968.1984.tb00743.x.

Vadillo-Rodríguez, V., H. J. Busscher, H. C. van der Mei, J. de Vries, and W. Norde. 2005. Role of lactobacillus cell surface hydrophobicity as probed by AFM in adhesion to surfaces at low and high ionic strength. Colloids Surf. B Biointerfaces 41:33-41. https://doi.org/10.1016/j.colsurfb.2004.10 .028 .

Woodward, R. P. 1999. Contact angle measurements using the drop shape method. First Ten Angstroms, Portsmouth, VA. https://www.jascoint.co.jp/ products/contact-angle/pdf/02.pdf.

Yu, S., Q. Wei, T. Zhao, Y. Guo, and L. Z. Ma. 2016. A survival strategy for Pseudomonas aeruginosa that uses exopolysaccharides to sequester and store iron to stimulate Psl-dependent biofilm formation. Appl. Environ. Microbiol. 82:6403-6413. https://doi.org/10.1128/AEM.01307-16.

\section{Notes}

Sanjeev Anand (D) https://orcid.org/0000-0002-7479-9965

This work was financially supported by The Midwest Dairy Association (St Paul, MN).

The authors acknowledge the support of the Agricultural Experimentation Station, the Electrical Engineering Department, and the Pharmacy Department and South Dakota State University (Brookings) for their support in carrying out this study.

The authors state that they have no conflicts of interest. 